\title{
Atypical presentations of coronavirus disease 2019 (COVID-19) from onset to readmission
}

\author{
Zhiqi Yang ${ }^{1+}$, Xiaofeng Chen ${ }^{1 \dagger}$, Ruibin Huang ${ }^{2+}$, Shengkai Li ${ }^{3}$, Daiying Lin ${ }^{4}$, Zhijian Yang ${ }^{5}$, Hongfu Sun ${ }^{6}$, \\ Guorui Liư ${ }^{7}$ Jinming Qiu', Yanyan Tang ${ }^{7}$, Jianning Xiao ${ }^{4}$, Yuting Liao ${ }^{8}$, Xianheng $\mathrm{Wu}^{4}$, Renhua $\mathrm{Wu}^{7}$, \\ Xiangguang Chen ${ }^{1 *}$ and Zhuozhi Dai ${ }^{7 *}$ (D)
}

\begin{abstract}
Background: To investigate the $\mathrm{CT}$ imaging and clinical features of three atypical presentations of coronavirus disease 2019 (COVID-19), namely (1) asymptomatic, (2) CT imaging-negative, and (3) re-detectable positive (RP), during all disease stages.

Methods: A consecutive cohort of 79 COVID-19 patients was retrospectively recruited from five independent institutions. For each presentation type, all patients were classified into atypical vs. typical groups (i.e., asymptomatic vs.symptomatic, CT imaging-negative vs. CT imaging-positive, and RP and non-RP, respectively). The chi-square test, Student's $t$ test, and Kruskal-Wallis $H$ test were performed to compare CT imaging and clinical features of atypical vs. typical patients for all three presentation categories.

Results: In our COVID-19 cohort, we found 12.7\% asymptomatic patients, 13.9\% CT imaging-negative patients, and 8.9\% RP patients. The asymptomatic patients had fewer hospitalization days $(P=0.043)$, lower total scores for bilateral lung involvement $(P<0.001)$, and fewer ground-glass opacities $(G G O s)$ in the peripheral area $(P<0.001)$ than symptomatic patients. The $C T$ imaging-negative patients were younger $(P=0.002)$, had a higher lymphocyte count $(P=0.038)$, had a higher lymphocyte rate $(P=0.008)$, and had more asymptomatic infections $(P=0.002)$ than the $C T$ imaging-positive patients. The RP patients with moderate COVID-19 had lower total scores of for bilateral lung involvement $(P=0.030)$ and a smaller portion of the left lung affected $(P=0.024)$ than non-RP patients. Compared to their first hospitalization, RP patients had a shorter hospitalization period $(P<0.001)$ and fewer days from the onset of illness to last RNA negative conversion $(P<0.001)$ at readmission.
\end{abstract}

Conclusions: Significant $C T$ imaging and clinical feature differences were found between atypical and typical COVID-19 patients for all three atypical presentation categories investigated in this study, which may help provide complementary information for the effective management of COVID-19.

Keywords: COVID-19, Asymptomatic, Re-detectable positive, CT imaging negative, Features

\footnotetext{
* Correspondence: cxg966504@163.com; zhuozhi@ualberta.ca

†Zhiqi Yang, Xiaofeng Chen and Ruibin Huang contributed equally to this work.

'Department of Radiology, Meizhou People's Hospital, Meizhou, Guangdong

514031, People's Republic of China

${ }^{7}$ Department of Radiology, 2nd Affiliated Hospital, Shantou University Medical College, Shantou, Guangdong 515000, People's Republic of China Full list of author information is available at the end of the article
}

(C) The Author(s). 2021 Open Access This article is licensed under a Creative Commons Attribution 4.0 International License, which permits use, sharing, adaptation, distribution and reproduction in any medium or format, as long as you give appropriate credit to the original author(s) and the source, provide a link to the Creative Commons licence, and indicate if changes were made. The images or other third party material in this article are included in the article's Creative Commons. licence, unless indicated otherwise in a credit line to the material. If material is not included in the article's Creative Commons licence and your intended use is not permitted by statutory regulation or exceeds the permitted use, you will need to obtain permission directly from the copyright holder. To view a copy of this licence, visit http://creativecommons.org/licenses/by/4.0/. The Creative Commons Public Domain Dedication waiver (http://creativecommons.org/publicdomain/zero/1.0/) applies to the data made available in this article, unless otherwise stated in a credit line to the data. 


\section{Background}

The coronavirus disease 2019 (COVID-19) pandemic is a global crisis and has caused hundreds of thousands of people to die as of June 8, 2020 [1]. Typical COVID-19 patients present with fever, cough, fatigue, normal white blood cell count (WBC), lower lymphocyte count, and pure or mixed ground-glass opacity (GGO) in the subpleural region [2-4]. However, prevention and control practices found that some patients did not present with these typical manifestations [5-7]. These patients challenge the prevention and control system and increase the risk of the COVID-19 spread. Identifying the atypical presentations is helpful for a comprehensive understanding of COVID-19 and infection control.

We categorized all patients into three atypical presentations of COVID-19: (1) asymptomatic, (2) CT imaging-negative, and (3) re-detectable positive (RP). In the early stages of COVID-19, asymptomatic and CT imaging-negative patients were easily overlooked and became hidden sources of infection. As an increasing number of patients are discharged, RP patients have gradually become the focus of attention. Recent studies have shown evidence of human-to-human transmission from asymptomatic patients [8-11]. CT imagingnegative and RP patients have also been reported in multiple studies [7, 12, 13]. However, limited data are available to provide a clear picture of the imaging and clinical features in all three types of atypical patients.

In this study, we aimed to identify the differences in CT imaging and clinical features from onset to discharge between typical and atypical patients with COVID-19 based on multicentre data. These data may help provide complementary information for more effective management of COVID-19.

\section{Materials and methods \\ Patients}

Ethical approval by the institutional review boards was obtained for this retrospective study, and the need to obtain informed consent was waived. From January 1 to April 22,020, a total of 79 consecutive patients with SARS-CoV-2 infection confirmed by real-time reverse transcription polymerase chain reaction (RT-PCR) were enrolled from 5 independent hospitals. Seventy-three patients were reported in our previous study [2, 3]. Of all patients, including 27 patients from Huizhou City, 27 from Shantou City, 15 from Yongzhou City and 10 from Meizhou City, the mean age was 41.8 years (range: 3 69 years). Overall, 69 patients were symptomatic (mean age: 42.2 years; range: $3 \sim 67$ years) and 10 were asymptomatic (mean age: 38.8 years; range: 16 69 years); additionally, 11 patients were CT imaging negative (mean age: 29.8 years; range: 3 48 years), and 68 were CT imaging positive (mean age: 43.7 years; range: 14 69 years).

According to the sixth edition guideline published by the National Health Commission of China [14], all discharged COVID-19 patients should be isolated and observed for 2 weeks. SARS-CoV-2 RNA detection from digestive and respiratory sites was performed weekly. The RP patients were readmitted to the hospital for further medical observation, and close contacts were also followed-up. As of April 30, 2020, all of the patients were followed up for at least 14 days, and 7 patients (8.9\%) were RP, including 4 patients from Huizhou City, 2 from Shantou City, and 1 from Meizhou City, with a mean age of 41.0 years old (range: 14 66 years). Among the RP patients, 4 were men (mean age: 37.8 years; range: $27 \sim 61$ years), and 3 were women (mean age: 45.3 years; range: $14 \sim 66$ years). Figure 1 shows the patient recruitment pathway of the symptomatic and

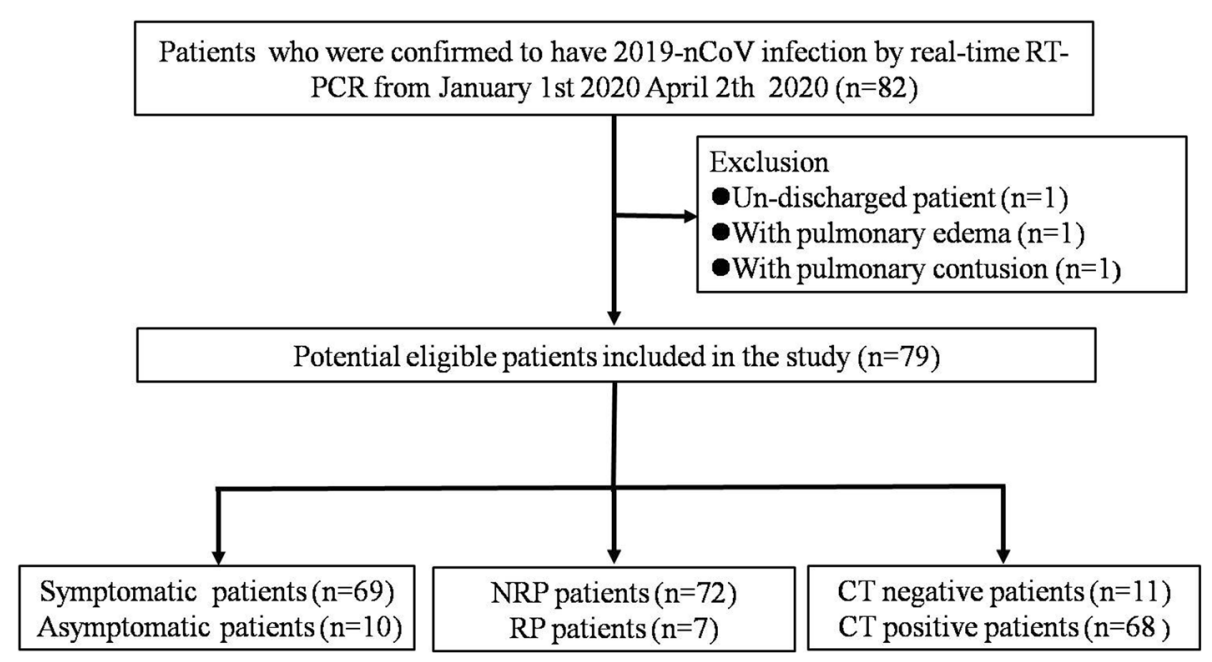

Fig. 1 Flow chart of patient selection and exclusion 

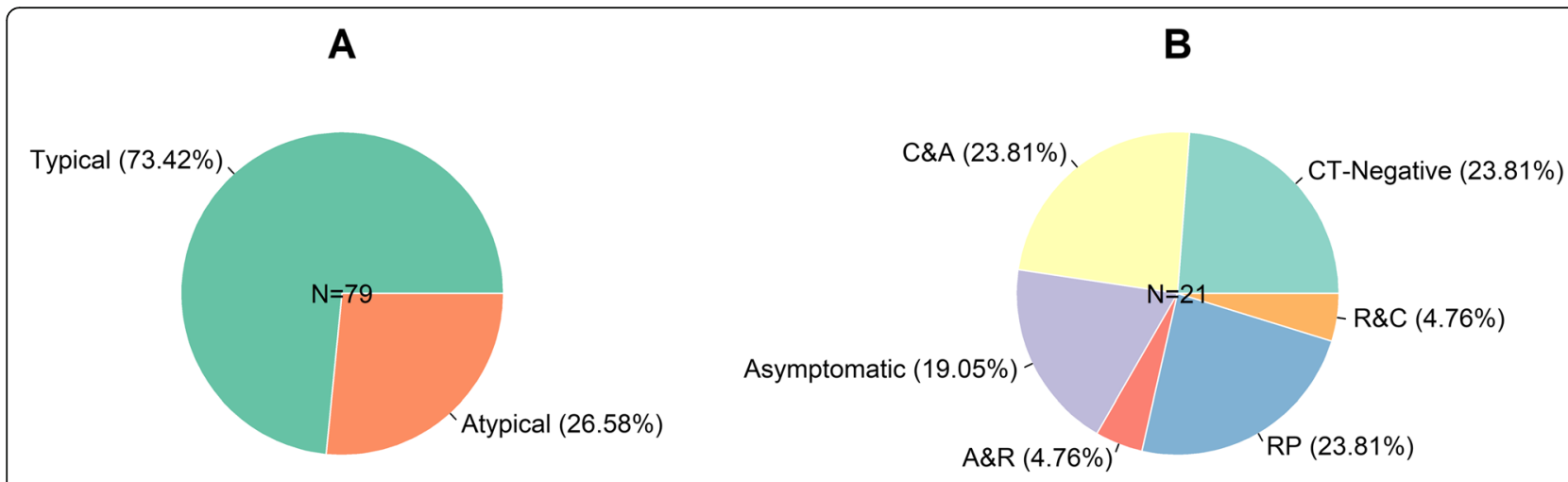

Fig. 2 Pie chart of COVID-19 patients. a: typical and atypical percentage of COVID-19 patients. b: CT-negative patients (C), asymptomatic patients (A), RP patients (R), and the combined percentage in atypical COVID-19 patients

asymptomatic infection patients, non-RP (NRP) and RP patients, CT imaging-negative and CT imaging-positive patients, along with the inclusion and exclusion criteria.

\section{Clinical data collection}

The initial clinical data from the first hospitalization and readmission, including age, sex, course of the disease, clinical symptoms, clinical type of COVID-19, hospitalization days, days from the onset of illness to the last RNA negative conversion, WBC count, lymphocyte count, lymphocyte ratio, neutrophil count and neutrophil ratio were collected. The threshold values for WBC count, lymphocyte count, lymphocyte ratio, neutrophil count and the neutrophil ratio were $3.5 \sim 9.5 \times 10^{9} / \mathrm{L}$,

Table 1 Clinical features of symptomatic and asymptomatic COVID-19 patients

\begin{tabular}{|c|c|c|c|}
\hline Features & Symptomatic $(n=69)$ & Asymptomatic $(n=10)$ & $P$-value \\
\hline Sex & & & $0.962^{\mathrm{a}}$ \\
\hline Male $^{\#}$ & $38(55.1 \%)$ & $6(60.0 \%)$ & \\
\hline Female $^{\#}$ & $31(44.9 \%)$ & $4(40.0 \%)$ & \\
\hline Age & $42.2 \pm 13.9$ & $38.8 \pm 17.1$ & $0.484^{\mathrm{b}}$ \\
\hline Course of disease & $2.51 \pm 2.63$ & $2.40 \pm 2.37$ & $0.903^{b}$ \\
\hline Clinical type & & & $0.001^{c *}$ \\
\hline Mild $^{\#}$ & $6(8.7 \%)$ & $5(50.0 \%)$ & \\
\hline Moderate $^{\#}$ & $56(81.2 \%)$ & $5(50.0 \%)$ & \\
\hline Severe ${ }^{\#}$ & $7(10.1 \%)$ & $0(0.0 \%)$ & \\
\hline Re-detectable of RNA after discharged & & & $1.00^{\mathrm{a}}$ \\
\hline Negative $^{\#}$ & $63(91.3 \%)$ & $9(90.0 \%)$ & \\
\hline Positive $^{\#}$ & $6(8.70 \%)$ & $1(10.0 \%)$ & \\
\hline Hospitalization days & $16.6 \pm 6.71$ & $12.0 \pm 5.85$ & $0.043^{\mathrm{b} *}$ \\
\hline Days of last RNA negative-conversion & $13.0 \pm 6.56$ & $10.4 \pm 5.93$ & $0.237^{b}$ \\
\hline Days of last RNA negative-conversion category & & & $0.319^{c}$ \\
\hline$<7$ days ${ }^{\#}$ & $9(13.0 \%)$ & $1(10.0 \%)$ & \\
\hline 7 days $\sim 14$ days ${ }^{\#}$ & $35(50.7 \%)$ & $8(80.0 \%)$ & \\
\hline 14 days $\sim 21$ days $^{\#}$ & $22(31.9 \%)$ & $0(0.0 \%)$ & \\
\hline$>21$ days $^{\#}$ & $3(4.4 \%)$ & $1(10.0 \%)$ & \\
\hline WBC count $\left(\times 10^{9} / L\right)$ & $5.51 \pm 2.50$ & $4.95 \pm 1.90$ & $0.502^{b}$ \\
\hline Lymphocyte count & $1.30 \pm 0.87$ & $1.37 \pm 0.39$ & $0.813^{b}$ \\
\hline Lymphocyte rate (\%) & $24.4 \pm 11.2$ & $30.7 \pm 11.7$ & $0.100^{\mathrm{b}}$ \\
\hline Neutrophil count $\left(\times 10^{9} / L\right)$ & $3.70 \pm 2.27$ & $3.15 \pm 1.89$ & $0.469^{b}$ \\
\hline Neutrophil rate (\%) & $65.0 \pm 14.8$ & $60.2 \pm 11.6$ & $0.328^{\mathrm{b}}$ \\
\hline
\end{tabular}


Table 2 CT features of symptomatic and asymptomatic COVID-19 patients

\begin{tabular}{|c|c|c|c|}
\hline Features & Symptomatic $(n=69)$ & Asymptomatic $(n=10)$ & $P$-value \\
\hline Overall condition of lesions & & & $<0.001^{c_{*}}$ \\
\hline Normal $^{\#}$ & $6(8.7 \%)$ & $5(50.0 \%)$ & \\
\hline Single & $4(5.8 \%)$ & $2(20.0 \%)$ & \\
\hline Multiple $^{\#}$ & $59(85.5 \%)$ & $3(30.0 \%)$ & \\
\hline \multicolumn{4}{|l|}{ Total number of GGO inperipheral area } \\
\hline Pure GGO & $5.36 \pm 7.28$ & $0.90 \pm 2.18$ & $<0.001^{b_{*}}$ \\
\hline Mixed GGO & $4.83 \pm 7.05$ & $0.50 \pm 0.85$ & $<0.001^{b_{*}}$ \\
\hline \multicolumn{4}{|l|}{ Total number of lesions } \\
\hline Peripheral area & $11.6 \pm 13.8$ & $1.40 \pm 2.22$ & $<0.001^{b_{*}}$ \\
\hline Central area & $1.81 \pm 4.41$ & $0.80 \pm 1.93$ & $0.478^{b}$ \\
\hline \multicolumn{4}{|l|}{ Total scores of involved lung zones } \\
\hline Bilateral lung & $5.26 \pm 4.01$ & $1.30 \pm 1.83$ & $<0.001^{b_{*}}$ \\
\hline Right lung & $3.01 \pm 2.45$ & $0.80 \pm 1.23$ & $<0.001^{b_{*}}$ \\
\hline Left lung & $2.25 \pm 1.86$ & $0.50 \pm 0.71$ & $<0.001^{b_{*}}$ \\
\hline \multicolumn{4}{|l|}{ Number of lobes affected } \\
\hline Right lung & $1.93 \pm 1.15$ & $0.80 \pm 1.23$ & $0.005^{\mathrm{b} *}$ \\
\hline Left lung & $1.39 \pm 0.79$ & $0.50 \pm 0.71$ & $0.001^{\mathrm{b} *}$ \\
\hline Total scores of bilateral lung category & & & $0.002^{\mathrm{a} *}$ \\
\hline$<3$ scores $^{\#}$ & $18(26.1 \%)$ & $8(80.0 \%)$ & \\
\hline$\geq 3$ scores $^{\#}$ & $51(73.9 \%)$ & $2(20.0 \%)$ & \\
\hline Pure GGO category & & & $0.021^{\mathrm{a*}}$ \\
\hline Negative $_{\#}^{\#}$ & $14(20.3 \%)$ & $6(60.0 \%)$ & \\
\hline Positive $^{\#}$ & $55(79.7 \%)$ & $4(40.0 \%)$ & \\
\hline Pure GGO in peripheral area category & & & $0.003^{\mathrm{a}^{*}}$ \\
\hline Negative ${ }^{\#}$ & $14(20.3 \%)$ & $7(70.0 \%)$ & \\
\hline Positive $^{\#}$ & $55(79.7 \%)$ & $3(30.0 \%)$ & \\
\hline Mixed GGO category & & & $0.003^{\mathrm{a} *}$ \\
\hline Negative $_{\#}^{\#}$ & $14(20.3 \%)$ & $7(70.0 \%)$ & \\
\hline Positive" & $55(79.7 \%)$ & $3(30.0 \%)$ & \\
\hline Mixed GGO in peripheral area category & & & $0.008^{\mathrm{a} *}$ \\
\hline Negative ${ }^{\#}$ & $16(23.2 \%)$ & $7(70.0 \%)$ & \\
\hline Positive $^{\#}$ & $53(76.8 \%)$ & $3(30.0 \%)$ & \\
\hline
\end{tabular}

Note: *Data with statistical significance. "Results are measurements with the corresponding ratio in parentheses, and the remainingresults are mean value with standard deviation. $P^{\mathrm{a}}$ : chi-square test, $P^{\mathrm{b}}$ : student's $t$-test, $P^{c}$ : Kruskal-Wallis $H$ test, GGO Ground-glass opacity

$1.1 \sim 3.2 \times 10^{9} / \mathrm{L}, \quad 20.0 \sim 50.0 \%, 1.8 \sim 6.3 \times 10^{9} / \mathrm{L}, \quad$ and $40.0 \sim 75.0 \%$, respectively, according to the normal range used at the individual hospital.

\section{CT image acquisition and review}

Non-contrast-enhanced chest CT imaging data were obtained from multiple hospitals using different CT systems, including GE CT Discovery 750 HD (General Electric, US), SCENARIA 64 CT (Hitachi Medical, Japan), PHILIPS Ingenuity CT (PHILIPS, Netherlands), and Siemens SOMATOM Definition AS (Siemens, Germany) systems. All images were reconstructed into $1 \mathrm{~mm}$ slices with a slice interval of $0.8 \mathrm{~mm}$. The detailed acquisition parameters are summarized in the supplementary material (Table E1).

The initial CT imaging from the first hospitalization for all patients and initial CT imaging at readmission for RP patients were evaluated. A total of 25 quantitative and 18 qualitative imaging features were extracted for analysis. The descriptions of the CT imaging features are listed in the supplementary material (Table E2 and Table E3). For the extraction of CT qualitative and quantitative imaging features, two senior radiologists (Z.Y. and X.C., more than 10 years of experience) reached a consensus and were blinded to the clinical and laboratory findings. A lesion in the outer third of the lung was defined as peripheral, and a lesion in the inner two-thirds was defined as central [2]. The classification of the lesion size was based on a previous study [2]. The progression of the lesion within each lung lobe was evaluated by scoring each lobe from 0 to 4 [2], corresponding to normal, $1 \% \sim 25 \%$ infection, $26 \% \sim 50 \%$ infection, 51\% 75\% infection and more than $75 \%$ infection, respectively. The scores were combined for all 5 lobes to provide a total score. 


\section{Statistical analysis}

For quantitative imaging features and qualitative imaging features, we use interclass correlation coefficients (ICC) and Cohen's Kappa to analyze the consistency of the two radiologists, respectively. The $\mathrm{CT}$ imaging and clinical features were compared between symptomatic and asymptomatic infection groups, NRP and RP patient groups, and CT imaging-negative and CT imagingpositive groups by using the chi-square test Fisher' $t$ test, the Student's $t$ test, and Kruskal-Wallis $H$ test. All statistical analyses were performed with $\mathrm{R}$ (version 3.6.4). All statistical tests were two-sided, and differences were considered significant at $P<0.05$.

\section{Results}

Baseline characteristics of COVID-19 patients

In our COVID-19 patients, 58 (73.42\%) had typical COVID-19, and 21 (26.58\%) had atypical COVID-19. In the atypical COVID-19 group, 5 (23.81\%) were CT imaging negative, 4 (19.05\%) were asymptomatic, 5 (23.81\%) were RP, 5 (23.81\%) were both CT imaging negative and asymptomatic, and 1 (4.76\%) was both asymptomatic and RP, 1 (4.76\%) was both RP and CT imaging negative (Fig. 2).

Clinical and CT imaging feature comparison between the symptomatic and asymptomatic infection groups

Consistency analysis result show than the ICC value of quantitative imaging features and kappa value of qualitative imaging features were greater than 0.95.The clinical features of the symptomatic and asymptomatic infection patients are shown in Table 1 . A total of $50.0 \%$ of asymptomatic infection patients had mild COVID-19 pneumonia. None of the asymptomatic infection patients developed severe COVID-19 pneumonia or died during follow-up. Compared to symptomatic infection patients, asymptomatic infection patients had a shorter hospitalization stay $(P=0.043)$. There was no significant difference in sex, age, rate of re-detectable RNA after discharge, days of last RNA negative conversion since the onset of illness, WBC count, lymphocyte count, lymphocyte rate, neutrophil countor and neutrophil rate between symptomatic and asymptomatic infection patients.

The CT imaging features of the symptomatic and asymptomatic infection patients are shown in Table E4, and those imaging features with significant differences are presented in Table 2. Representative CT images from symptomatic and asymptomatic infection patients are shown in Fig. 3. A total of $50.0 \%$ asymptomatic infection patients had normal chest CT imaging. Compared to symptomatic infection patients, asymptomatic infection patients had a smaller total number of pure GGOs in the peripheral area $(P<0.001)$, mixed GGOs in the peripheral area $(P<0.001)$, total number of lesions in the peripheral area $(P<0.001)$, proportion of the left lobe affected $(P=0.005)$, and proportion of the right lobe affected $(P=0.001)$, as well as lower total bilateral lung scores $(P<0.001)$, and lower total right lung scores $(P<0.001)$ and left lung scores $(P<0.001)$. In addition, the

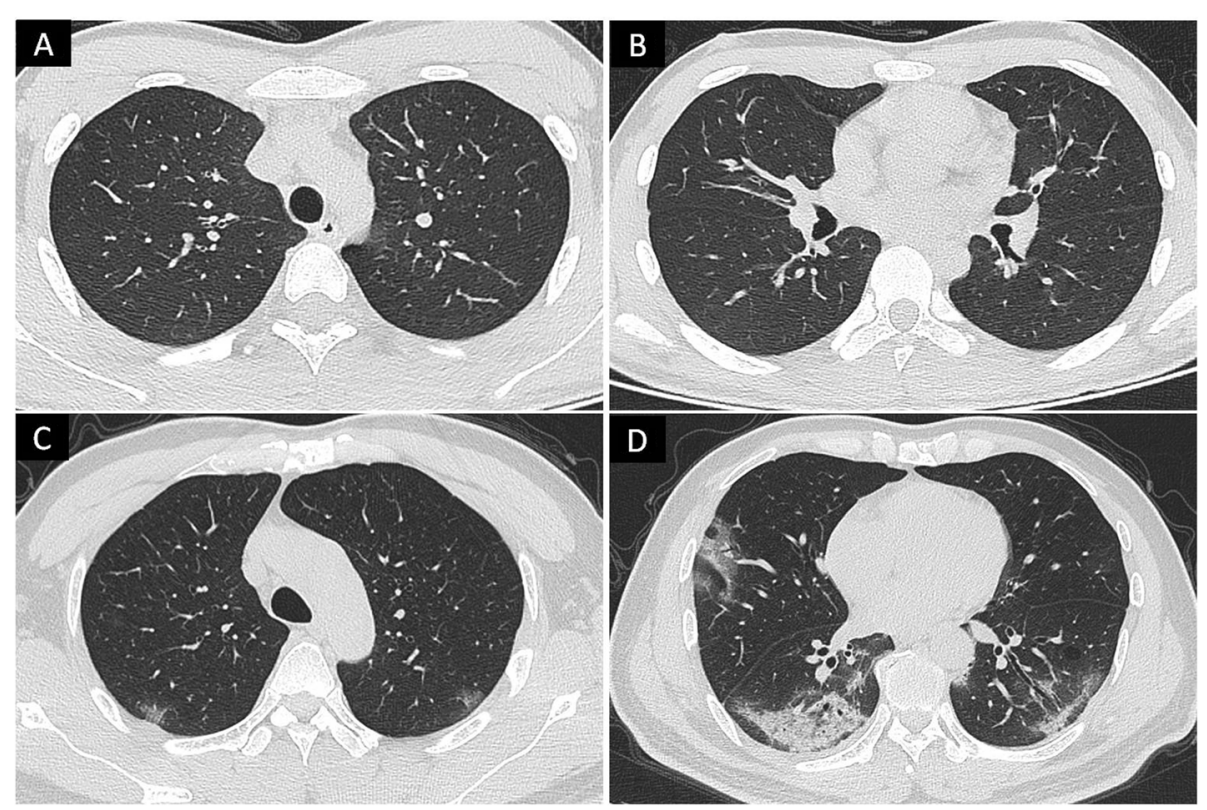

Fig. 3 3a-3b: Asymptomatic infection with moderate COVID-19 patient. There are one pure ground-glass opacities under pleural of right lung upper lobe. The remaining double lung did not see obvious abnormalities. The total scores of involved zones in the bilateral lung is $1.3 \mathbf{c}-3 \mathbf{d}$ : Symptomatic infection with moderate COVID-19 patient. There are multiple pure and mixed ground-glass opacities under double lung pleural. The total scores of involved zones in the bilateral lung is 6 
negative rates of pure GGOs (60.0\%), pure GGOs in peripheral areas (70.0\%), mixed GGOs (70.0\%), and mixed GGOs in peripheral areas (70.0\%) were more pronounced in asymptomatic infection patients (all $P<0.05$ ).

\section{Clinical feature comparison between the CT-negative and CT-positive patient groups}

The clinical features of the CT imaging-negative and CT imaging-positive patients are listed in Table 3. Compared to CT imaging-positive patients, CT imaging -negative patients were younger and had higher lymphocyte counts, higher lymphocyte rates, and more asymptomatic infections (45.5\%). In addition, CT imaging-negative patients presented with more asymptomatic infections than the CT imaging-positive patients $(P<0.001)$. There was no significant difference in sex, course of the disease, hospitalization days, or days since last RNA negative conversion between the CT-negative and CT-positive patients.
Clinical and CT imaging feature comparison between the NRP and RP patient groups

As of April 232,020, 79 patients were followed up for at least 14 days, and 7 patients were re-detected as positive for SARSCoV-2 during follow-up. The clinical features of the NRP and RP patients are shown in Table 4. Among the RP patients, 6 were moderate COVID-19 patients, and 1 was a mild COVID-19 patient. None of patients developed severe COVID-19 pneumonia during hospitalization. Most RP patients had clinical symptoms (85.7\%). There was no significant difference in sex, age, course of the disease, hospitalization days, days since last RNA negative conversion,or clinical laboratory findings between the NRP and RP patients.

The CT imaging features of the NRP and RP patients are shown in Table E5, and those imaging features with significant differences are presented in Table 5. Representative CT images from the NRP and RP patients are shown in Fig. 4. Among them, only the occurrence rates of mixed GGOs and mixed GGOs in the peripheral area

Table 3 Clinical features of CT negativeand positive patients with COVID-19

\begin{tabular}{|c|c|c|c|}
\hline Features & $\begin{array}{l}\text { CT- negative } \\
(n=11)\end{array}$ & $\begin{array}{l}\text { CT-positive } \\
(n=68)\end{array}$ & $P$-value \\
\hline$\overline{S e x}$ & & & $0.807^{\mathrm{a}}$ \\
\hline Male & $6(54.5 \%)$ & $38(55.9 \%)$ & \\
\hline Female\# & $5(45.5 \%)$ & $30(44.1 \%)$ & \\
\hline Age & $29.8 \pm 11.9$ & $43.7 \pm 13.8$ & $0.002^{b_{*}}$ \\
\hline Course of disease & $2.09 \pm 2.26$ & $2.56 \pm 2.64$ & $0.580^{\mathrm{b}}$ \\
\hline Clinical types & & & $<0.001^{c *}$ \\
\hline Mild $^{\#}$ & $11(100 \%)$ & $0(0.0 \%)$ & \\
\hline Moderate ${ }^{\#}$ & $0(0.0 \%)$ & $61(89.7 \%)$ & \\
\hline Severe ${ }^{\#}$ & $0(0.0 \%)$ & $7(10.3 \%)$ & \\
\hline Symptoms & & & $0.002^{a *}$ \\
\hline Symptomatic ${ }^{\#}$ & $6(54.5 \%)$ & 63(92.6\%) & \\
\hline Asymptomatic ${ }^{\#}$ & $5(45.5 \%)$ & $5(7.4 \%)$ & \\
\hline Re-detectable of RNA after discharged & & & $1.00^{\mathrm{a}}$ \\
\hline Negative $^{\#}$ & $10(90.9 \%)$ & $62(91.2 \%)$ & \\
\hline Positive ${ }^{\#}$ & $1(9.1 \%)$ & $6(8.8 \%)$ & \\
\hline Hospitalization days & $12.6 \pm 6.01$ & $16.6 \pm 6.74$ & $0.065^{b}$ \\
\hline Days of last RNA negative-conversion & $9.73 \pm 5.80$ & $13.2 \pm 6.53$ & $0.105^{b}$ \\
\hline Days of last RNA negative-conversion category & & & $0.056^{c}$ \\
\hline$<7$ days ${ }^{\#}$ & $3(27.3 \%)$ & $7(10.3 \%)$ & \\
\hline 7 days to 14 days $\#$ & $7(63.6 \%)$ & $36(52.9 \%)$ & \\
\hline 14 days to 21 days" & $0(0.0 \%)$ & $22(32.4 \%)$ & \\
\hline$>21$ days ${ }^{\#}$ & $1(9.1 \%)$ & $3(4.4 \%)$ & \\
\hline WBC count $\left(\times 10^{9} / \mathrm{L}\right)$ & $6.22 \pm 2.24$ & $5.31 \pm 2.45$ & $0.249^{b}$ \\
\hline Lymphocyte count & $2.23 \pm 1.48$ & $1.16 \pm 0.55$ & $0.038^{\mathrm{b*}}$ \\
\hline Lymphocyte rate (\%) & $33.5 \pm 13.2$ & $23.8 \pm 10.5$ & $0.008^{b *}$ \\
\hline Neutrophil count $\left(\times 10^{9} / \mathrm{L}\right)$ & $3.59 \pm 1.82$ & $3.64 \pm 2.30$ & $0.955^{b}$ \\
\hline Neutrophil rate (\%) & $57.1 \pm 13.9$ & $65.6 \pm 14.3$ & $0.070^{\mathrm{b}}$ \\
\hline
\end{tabular}


Table 4 Clinical features of RP and NRP patients with COVID-19

\begin{tabular}{|c|c|c|c|}
\hline Features & NRP patients $(n=72)$ & RP patients(n=7) & $P$-value \\
\hline \multicolumn{4}{|l|}{ Sex } \\
\hline Male & $40(55.6 \%)$ & $4(57.1 \%)$ & $0.751^{\mathrm{a}}$ \\
\hline Female $^{\#}$ & $32(44.4 \%)$ & $3(42.9 \%)$ & \\
\hline Age & $41.9 \pm 13.8$ & $41.0 \pm 19.8$ & $0.880^{\mathrm{b}}$ \\
\hline Course of disease & $2.50 \pm 2.58$ & $2.43 \pm 2.82$ & $0.950^{\mathrm{b}}$ \\
\hline Clinical types & & & $0.604^{c}$ \\
\hline Mild ${ }^{\#}$ & 10(13.9\%) & $1(14.3 \%)$ & \\
\hline Moderate $^{\#}$ & $55(76.4 \%)$ & $6(85.7 \%)$ & \\
\hline Severe ${ }^{\#}$ & $7(9.70 \%)$ & $0(0.0 \%)$ & \\
\hline Symptoms & & & $1.00^{\mathrm{a}}$ \\
\hline Symptomatic ${ }^{\#}$ & $63(87.5 \%)$ & $6(85.7 \%)$ & \\
\hline Asymptomatic ${ }^{\#}$ & $9(12.5 \%)$ & $1(14.3 \%)$ & \\
\hline Hospitalization days & $15.8 \pm 6.86$ & $18.3 \pm 5.35$ & $0.357^{b}$ \\
\hline Days of last RNA negative-conversion & $12.4 \pm 6.58$ & $15.3 \pm 5.38$ & $0.270^{b}$ \\
\hline Days of last RNA negative-conversion category & & & $0.096^{c}$ \\
\hline$<7$ days $^{\#}$ & $10(13.9 \%)$ & $0(0.0 \%)$ & \\
\hline 7 days to 14 days ${ }^{\#}$ & $40(55.6 \%)$ & $3(42.8 \%)$ & \\
\hline 14 days to 21 days ${ }^{\#}$ & $19(26.4 \%)$ & $3(42.9 \%)$ & \\
\hline$>21$ days $^{\#}$ & $3(4.1 \%)$ & $1(14.3 \%)$ & \\
\hline WBC count $\left(\times 10^{9} / \mathrm{L}\right)$ & $5.28 \pm 2.30$ & $7.07 \pm 3.29$ & $0.062^{b}$ \\
\hline Lymphocyte count & $1.32 \pm 0.86$ & $1.22 \pm 0.38$ & $0.763^{b}$ \\
\hline Lymphocyte rate (\%) & $25.6 \pm 11.4$ & $21.0 \pm 10.4$ & $0.313^{b}$ \\
\hline Neutrophil count $\left(\times 10^{9} / L\right)$ & $3.48 \pm 2.01$ & $5.14 \pm 3.23$ & $0.228^{b}$ \\
\hline Neutrophil rate (\%) & $64.4 \pm 14.3$ & $63.9 \pm 17.6$ & $0.931^{b}$ \\
\hline
\end{tabular}

Note:*Data with statistical significance. " Results are measurements with corresponding ratio in parentheses, and the remainder results are mean value with standard deviation. $P^{\mathrm{a}}$ : chi square test, $P^{\mathrm{b}}$ : student's $t$ test, $P^{\complement}$ : Kruskal-Wallis $H$ test, WBC White blood cell

were significantly different between the NRP and RP patients (all $P<0.05$ ). Compared to NRP patients, negative rates of mixed GGOs (71.4\%) and mixed GGOs in the peripheral area $(71.4 \%)$ were more pronounced in the RP patients. Because most RP patients $(85.7 \%)$ had moderate COVID-19 pneumonia, further analysisof the moderate COVID-19 patients revealed that RP patients with moderate COVID-19 had a smaller proportion of the left lung affected than the NRP patients $(0.83 \pm 0.75$ vs $1.53 \pm$ $0.69, P=0.024)$. In addition, total bilateral lung scores $<3$ were more prevalent in RP patients with moderate COVID-19 than in NRP patients with moderate COVID-19 (66.7\% vs.18.2\%, $P=0.030)$.

\section{Baseline characteristics of RP patients at first hospitalization and readmission}

All RP patients were readmitted to the hospital for further medical observation. The baseline characteristics of RP patients at first hospitalization and readmission are shown in Table 6. No patient had a fever or noticeable disease progression during readmission. The prevalence of fatigue and runny nose were decreased compared with the prior admission $(14.3 \%$ vs 28.8 and $0.00 \%$ vs $14.3 \%$, respectively). All RP patients had stable COVID-19 and their WBC count, lymphocyte count, lymphocyte rate, neutrophil count and neutrophil rate were wihtin the normal range. The total bilateral lung scores were reduced in RP patients at readmission compared with the scores at the first hospitalization $(1.14 \pm 0.69$ vs $3.00 \pm 3.65)$. Compare to the first hospitalization, RP patients had a shorter hospitalization period $(P<0.001)$ and fewer days between the onset of illness and last RNA negative conversion $(P<$ $0.001)$ at readmission. In addition, because all discharged COVID-19 patients in our cohort required isolation at home, only 3 close contacts were followed up. As of April 30,2020 , all the close contacts were tested, and all were negative for SARS-CoV-2. No suspicious clinical symptoms were reported in those close contacts.

\section{Discussion}

In this study, we retrospectively analyzed data from onset to discharge for five independent COVID-19 groups 
Table 5 CT imaging features of RP and NRP patients with COVID-19

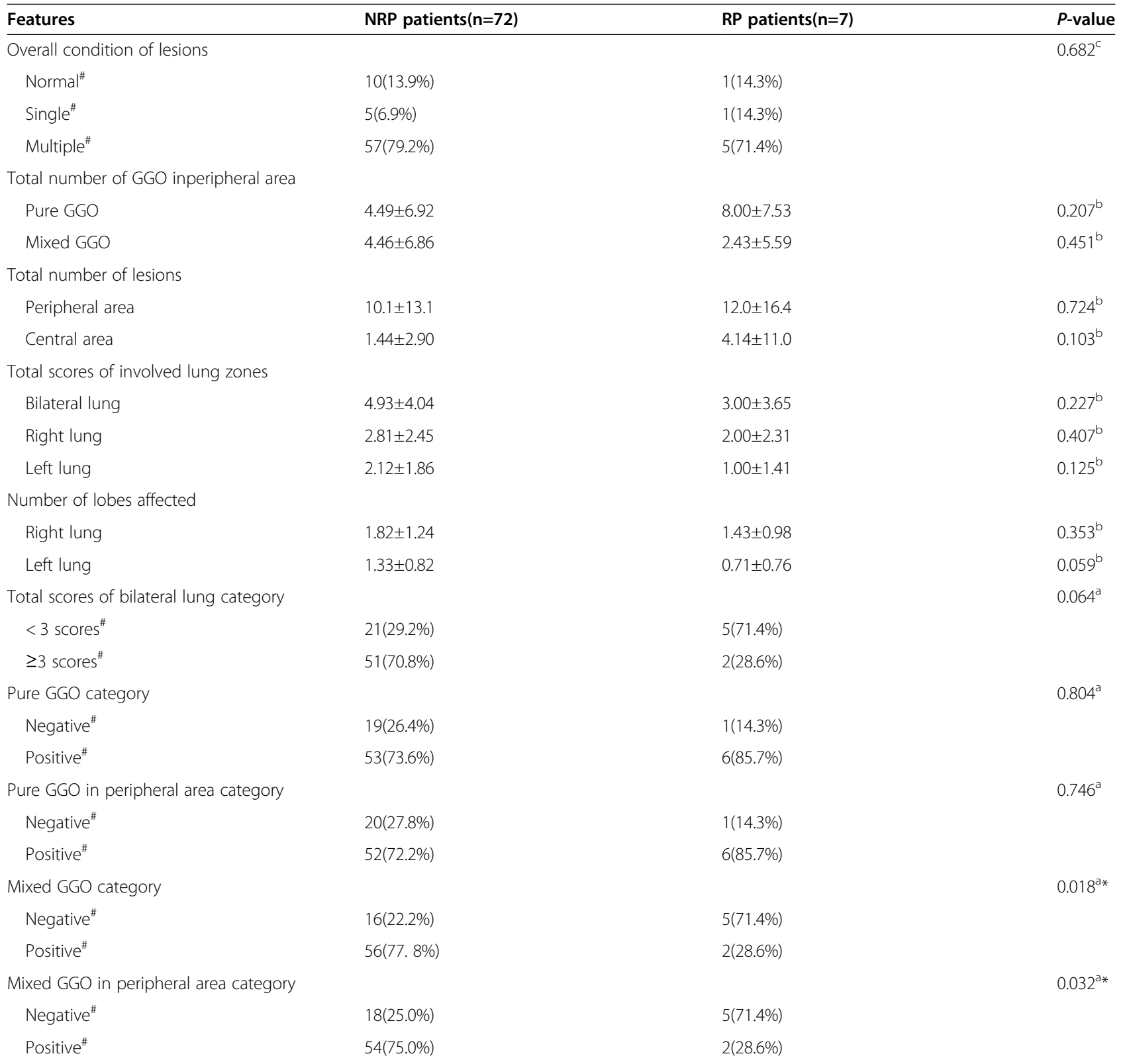

Note: *Data with statistical significance. "Results are measurements with corresponding ratio in parentheses, and the remainder results are mean value with standard deviation. $P^{\mathrm{a}}$ : chi square test, $P^{\mathrm{b}}$ : student's $t$ test, $P^{\mathrm{c}}$ : Kruskal-Wallis $H$ test, GGO Ground-glass opacity

from four different cities: re-detectable positivity and repeat hospitalization, and discharge were evaluated. We found that $26.6 \%$ of patients had atypical presentations of COVID-19, including asymptomatic, CT imagingnegative, and RP presentations. By comparing CT imaging and clinical characteristics between typical and atypical patients with COVID-19, 14 imaging features and 2 clinical characteristics were significantly different between symptomatic and asymptomatic COVID-19 patients. Five clinical characteristics were significantly different between CT-negative and CT-positive patients. Two imaging features were significantly different between RP and NRP patients with a moderate-severity COVID-19. Two clinical features were significantly different between the first hospitalization and readmission in RP patients.

Asymptomatic patients were first reported and shown to be contagious by Bai et al. [15]. In our study, half of the asymptomatic patients were mild cases, and the other half were moderate cases. In line with previous studies $[8,16]$, none of the asymptomatic patients developed severe COVID-19 pneumonia, and the hospitalization stays of asymptomatic patients were shorter than those of symptomatic patients. In a 


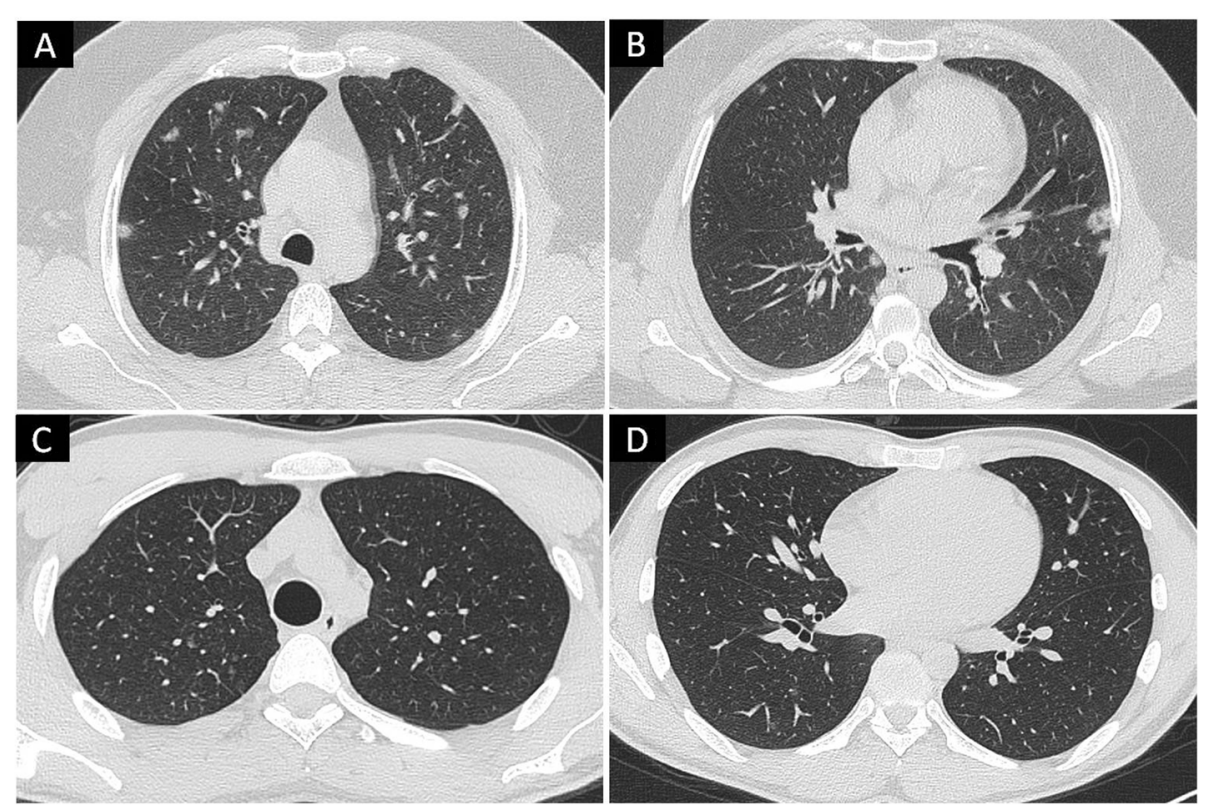

Fig. 4 4a-4b: Moderate COVID-19, non-re-detectable positive patient. There are multiple pure and mixed ground-glass opacities under double lung pleural. The total scores of involved zones in the bilateral lung is 4. 4c-4d: Moderate COVID-19, re-detectable positive patient. There are multiple pure ground-glass opacities under upper and lower lobe pleural of the right lung. The total scores of involved zones in the bilateral lung is 2

previous study, GGOs with a peripheral distribution were demonstrated to be the predominant feature of the CT findings in asymptomatic cases of COVID-19 [16]. Our findings also showed that asymptomatic patients had lower total bilateral lung scores and a smaller total number of GGOs in the peripheral area, indicating milder pneumonia in these patients. Since $80 \%$ of asymptomatic patients had a score of lower than 3 points and more than $73 \%$ of symptomatic patients had a score of higher than 3 points, we speculate that a total score of 3 can be used as a threshold.

The CT imaging-negative patients was significantly younger than the CT imaging-positive patients. Similarly, $\mathrm{Ai}$ et al. demonstrated that the positive predictive values and accuracy of chest CT in diagnosing COVID-19 were higher in patients $\geq 60$ years than in patients $<60$ years [17]. A recent study further revealed that most COVID19-positive children had negative chest CT scans [18]. Due to the presence of CT imaging-negative patients, The use of CT as a diagnostic tool for COVID-19 is becoming controversial [19]. Multiple radiological organizations have suggested that $\mathrm{CT}$ should not be used to screen for or as a first-line test to diagnose COVID-19 [20-22]. Nevertheless, CT imaging plays an important role in the diagnosis and treatment of COVID-19 [3, 23]. In this study, we also found that half of the asymptomatic patients had negative CT imaging results. This evidence supports the statement that CT scanning is not a perfect tool for COVID-19 screening. However, the above evidence also indicates that the patient age can be one of the essential reference standards for chest CT usage: the use of CT may be more appropriate in elderly patients.

As an incerasing number of patients are cured and discharged from the hospital, RP patients with COVID-19 have become the focus of prevention. Several case reports noted that some COVID-19 patients test positive days after recovery [7, 24]; most cases were of mild and moderate severity [25]. Consistent with previous research, our findings demonstrated that no severe patient with COVID-19 developed RP. Moreover, most RP patients had a total lung involvement score of less than 3 , which is similar in asymptomatic patients, confirming that the total lung involvement score is an effective indicator for classifying typical and atypical COVID-19 patients. The contagiousness of RP patients is still unclear, and some believe that the positive PCR results are from specific gene fragments that have no contagiousness [26, 27]. In our study, we found that all close contacts with RP patients were negative for SARS-CoV-2. However, it is worth noting that some RP patients previously had a high viral load of SARS-CoV-2 nucleic acid [28]. Therefore, COVID-19 prevention should not end at discharge, and a proper extension of the quarantine time after discharge may be required. Fortunately, our study suggests that the number of days sincer last RNA negative conversion are much fewer in RP patients when they are readmitted to the hospital than at their fist admission.

There are several limitations to this study. First, the asymptomatic population may be underestimated since it is difficult to estimate how many people become 
Table 6 Baseline characteristics of RP patients at first hospitalization and readmission

\begin{tabular}{|c|c|c|c|}
\hline Features & $\begin{array}{l}\text { First hospitalization } \\
(n=7)\end{array}$ & $\begin{array}{l}\text { Re-admission } \\
(n=7)\end{array}$ & $P$-value \\
\hline \multicolumn{4}{|l|}{ Signs } \\
\hline Fever ${ }^{\#}$ & $2(28.6 \%)$ & $0(0.0 \%)$ & $1.00^{\mathrm{d}}$ \\
\hline Cough $^{\#}$ & $3(42.9 \%)$ & $3(42.9 \%)$ & $1.00^{\mathrm{a}}$ \\
\hline Fatigue $e^{\#}$ & $2(28.8 \%)$ & $1(14.3 \%)$ & $1.00^{\mathrm{a}}$ \\
\hline Runny nose ${ }^{\#}$ & $1(14.3 \%)$ & $0(0.0 \%)$ & $1.00^{\mathrm{d}}$ \\
\hline Clinical types & & & $1.00^{\mathrm{a}}$ \\
\hline Mild ${ }^{\#}$ & $1(14.3 \%)$ & $1(14.3 \%)$ & \\
\hline Moderate ${ }^{\#}$ & $6(85.7 \%)$ & $6(85.7 \%)$ & \\
\hline Hospitalization days & $18.3 \pm 5.35$ & $6.57 \pm 1.62$ & $<0.001^{\mathrm{b} *}$ \\
\hline Days of last RNA negative-conversion & $15.3 \pm 5.38$ & $3.57 \pm 1.90$ & $<0.001^{\mathrm{b} *}$ \\
\hline WBC count $\left(\times 10^{9} / \mathrm{L}\right)$ & $7.07 \pm 3.29$ & $6.42 \pm 1.51$ & $0.642^{\mathrm{b}}$ \\
\hline Lymphocyte count & $1.22 \pm 0.38$ & $1.56 \pm 0.39$ & $0.124^{b}$ \\
\hline Lymphocyte rate (\%) & $21.0 \pm 10.4$ & $25.3 \pm 6.78$ & $0.378^{\mathrm{b}}$ \\
\hline Neutrophil count $\left(\times 10^{9} / \mathrm{L}\right)$ & $5.14 \pm 3.23$ & $3.97 \pm 1.20$ & $0.385^{b}$ \\
\hline Neutrophil rate (\%) & $63.9 \pm 17.6$ & $62.0 \pm 6.51$ & $0.791^{b}$ \\
\hline Chest $C T$ & & & $1.00^{\mathrm{a}}$ \\
\hline Normal $^{\#}$ & $1(14.3 \%)$ & $1(14.3 \%)$ & \\
\hline Abnormal $^{\#}$ & $6(85.7 \%)$ & $6(85.7 \%)$ & \\
\hline Total scores of bilateral lung & $3.00 \pm 3.65$ & $1.14 \pm 0.69$ & $0.211^{\mathrm{b}}$ \\
\hline Pure GGO category & & & $1.00^{\mathrm{a}}$ \\
\hline Negative $^{\#}$ & $1(14.3 \%)$ & $1(14.3 \%)$ & \\
\hline Positive & $6(85.7 \%)$ & $6(85.7 \%)$ & \\
\hline Pure GGO in peripheral area category & & & $1.00^{\mathrm{a}}$ \\
\hline Negative $^{\#}$ & $1(14.3 \%)$ & $2(28.6 \%)$ & \\
\hline Positive $^{\#}$ & $6(85.7 \%)$ & $5(71.4 \%)$ & \\
\hline Mixed GGO category & & & $0.192^{d}$ \\
\hline Negative $^{\#}$ & $4(57.1 \%)$ & $7(100 \%)$ & \\
\hline Positive $^{\#}$ & $3(42.9 \%)$ & $0(0.0 \%)$ & \\
\hline Mixed GGO in peripheral area category & & & $0.192^{d}$ \\
\hline Negative ${ }^{\#}$ & $4(57.1 \%)$ & $7(100 \%)$ & \\
\hline Positive $^{\#}$ & $3(42.9 \%)$ & $0(0.0 \%)$ & \\
\hline
\end{tabular}

Note: *Data with statistical significance. "Results are measurements with the corresponding ratio in parentheses, and the remainingresults are mean value with standard deviation. $P^{\mathrm{a}}$ : chi-square test, $P^{\mathrm{b}}$ : student's $t$-test, $P^{\mathrm{d}}$ : Fisher'test. WBC White blood cell

infected without showing symptoms. In this study, only close contacts of the COVID-19 patients were tracked. Population-wide testing is needed in further studies. Second, antibody tests such as IgG and IgM tests were missing in our study since this technology had not been utilized in the partcipant hospitals at that time. Further research that incorporates blood antibody tests may better detect false-negative PCR cases.

\section{Conclusions}

In conclusion, we analyzed the atypical presentations of COVID-19 from onset to readmission, including patients with asymptomatic, CT imaging negative, and RP presentations. Significant CT imaging and clinical feature differences were found between atypical and typical COVID-19 patients for all three presentation, which helps provide complementary information for the effective management of COVID-19.

\section{Supplementary Information}

The online version contains supplementary material available at https://doi. org/10.1186/s12879-020-05751-8.

\section{Additional file 1.}




\section{Abbreviations}

COVID-19: Coronavirus disease 2019; GGO: Ground-glass opacity; RTPCR: Reverse transcription polymerase chain reaction; WBC: White blood cell; AUC: Area under the curve; SARS: Severe acute respiratory syndrome; MERS: Middle east respiratory syndrome

\section{Acknowledgments}

This work was supported by grants from the Natural Science Foundation of China [grant number 81471730, 31870981] to R.W.; the 2020 LKSF crossdisciplinary research grants [grant number 2020LKSFBME06]; the Natural Science Foundation of Guangdong Province [grant number 2018A030307057] to Z.D.; and the Department of Education of Guangdong Province (grant number 2020KZDZX1085) to Z.D.

\section{Authors' contributions}

Z.D, X. C, and Z.Y. ${ }^{1}$ put forward the study concepts, then Z.Y Y X. C, R.H and Z. D designed the study. Data acquisition was done by S. L, D. L, Z.Y., , H. S, G. L, J. Q, Y. T, J. X, X. W and R.W. Y. L made statistical analysis. Z.Y, X. C and R. H were major contributors and contributed equally in writing the manuscript. All authors read and approved the final manuscript.

\section{Funding}

the Natural Science Foundation of China [grant number 81471730, 31870981] to R.W.tthe 2020 LKSF cross-disciplinary research grants [grant number 2020LKSFBME06]; the Natural Science Foundation of Guangdong Province [grant number 2018A030307057] to Z.D.; the Department of Education of Guangdong Province (grant number 2020KZDZX1085) to Z.D. The funding body had no role in the design of the study andcollection, analysis, and interpretation of data and in writing the manuscript.

\section{Availability of data and materials}

The data cohorts used and/or analyzed during the present study are available from the corresponding author on reasonable request.

\section{Ethics approval and consent to participate}

The study was approved by the institutional review board at the Meizhou People's Hospital, which waived the requirement for patients' informed consent referring to the CIOMS guideline. All the data used in this study was anonymised before its use

\section{Consent for publication}

Not applicable.

\section{Competing interests}

The authors declare that they have no competing interests.

\section{Author details}

'Department of Radiology, Meizhou People's Hospital, Meizhou, Guangdong 514031, People's Republic of China. ${ }^{2}$ Department of Radiology, First Affiliated Hospital, Shantou University Medical College, Shantou, Guangdong 515041, People's Republic of China. ${ }^{3}$ Department of Radiology, Huizhou Municipal Central Hospital, Huizhou 516001, Guangdong, China. ${ }^{4}$ Department of Radiology, Shantou Central Hospital, Shantou, Guangdong 515041, People's Republic of China. ${ }^{5}$ Department of Radiology, Yongzhou People's Hospital, Yongzhou, Hunan 425006, People's Republic of China. ${ }^{6}$ School of Information Technology and Electrical Engineering, University of Queensland, Brisbane, Queensland 4072, Australia. ${ }^{7}$ Department of Radiology, 2nd Affiliated Hospital, Shantou University Medical College, Shantou, Guangdong 515000, People's Republic of China. ${ }^{8}$ GE Healthcare, Guangzhou 510623, China.

Received: 24 July 2020 Accepted: 27 December 2020 Published online: 29 January 2021

\section{References}

1. Organization WH. Novel Coronavirus (2019-nCoV) situation reports 2020 [cited 2020 June 8]. Available from: https:/www.who.int/emergencies/ diseases/novel-coronavirus-2019/situation-reports/.

2. Chen X, Tang Y, Mo Y, Li S, Lin D, Yang Z, Yang Z, Sun H, Qiu J, Liao Y, Xiao J, Chen X, Wu X, Wu R, Dai Z. A diagnostic model for coronavirus disease 2019 (COVID-19) based on radiological semantic and clinical features: a multi-center study. Eur Radiol. 2020. https://doi.org/10.1007/s00330-02006829-2 Epub 2020/04/18. PubMed PMID: 32300971.

3. Yang Z, Lin D, Chen X, Qiu J, Li S, Huang R, Sun H, Liao Y, Xiao J, Tang Y, Liu G, Wu R, Chen X, Dai Z. Distinguishing COVID-19 from influenza pneumonia in the early stage through $\mathrm{CT}$ imaging and clinical features. medRxiv. 2020: 2020.04.17.20061242.. https://doi.org/10.1101/2020.04.17.20061242.

4. Chung M, Bernheim A, Mei X, Zhang N, Huang M, Zeng X, Cui J, Xu W, Yang Y, Fayad ZA, Jacobi A, Li K, Li S, Shan H. CT Imaging Features of 2019 Novel Coronavirus (2019-nCoV). Radiology. 2020;295(1):202-7. https://doi. org/10.1148/radiol.2020200230 Epub 2020/02/06. PubMed PMID: 32017661.

5. Zhang JF, Yan K, Ye HH, Lin J, Zheng JJ, Cai T. SARS-CoV-2 turned positive in a discharged patient with COVID-19 arouses concern regarding the present standard for discharge. Int J Infect Dis. 2020. https://doi.org/10. 1016/j.jij.2020.03.007 Epub 2020/03/23. PubMed PMID: 32200109.

6. Qu YM, Kang EM, Cong HY. Positive result of Sars-Cov-2 in sputum from a cured patient with COVID-19. Travel Med Infect Dis. 2020:101619. https:// doi.org/10.1016/j.tmaid.2020.101619. Epub 2020/03/13. PubMed PMID: 32160971; PubMed Central PMCID: PMCPMC7129439 interest to declare.

7. Lan L, Xu D, Ye G, Xia C, Wang S, Li Y, Xu H. Positive RT-PCR Test Results in Patients Recovered From COVID-19. Jama. 2020. https://doi.org/10.1001/ jama.2020.2783 Epub 2020/02/28. PubMed PMID: 32105304; PubMed Central PMCID: PMCPMC7047852.

8. Hu Z, Song C, Xu C, Jin G, Chen Y, Xu X, Ma H, Chen W, Lin Y, Zheng Y, Wang J, Hu Z, Yi Y, Shen H. Clinical characteristics of 24 asymptomatic infections with COVID-19 screened among close contacts in Nanjing, China. Sci China Life Sci. 2020. https://doi.org/10.1007/s11427-020-1661-4. Epub 2020/03/09. PubMed PMID: 32146694.

9. Sutton D, Fuchs K, D'Alton M, Goffman D. Universal Screening for SARS-CoV2 in Women Admitted for Delivery. New Engl J Med. 2020;382(22):2163-4. https://doi.org/10.1056/NEJMc2009316.

10. Zhang J, Tian S, Lou J, Chen Y. Familial cluster of COVID-19 infection from an asymptomatic. Critical Care. 2020;24(1):119. https://doi.org/10.1186/ s13054-020-2817-7 Epub 2020/03/30. PubMed PMID: 32220236; PubMed Central PMCID: PMCPmc7100442.

11. Li C, Ji F, Wang L, Wang L, Hao J, Dai M, Liu Y, Pan X, Fu J, Li L, Yang G, Yang J, Yan X, Gu B. Asymptomatic and Human-to-Human Transmission of SARS-CoV-2 in a 2-Family Cluster, Xuzhou, China. Emerg Infect Dis. 2020; 26(7). https://doi.org/10.3201/eid2607.200718. Epub 2020/04/02. PubMed PMID: 32228809 .

12. Song F, Shi N, Shan F, Zhang Z, Shen J, Lu H, Ling Y, Jiang Y, Shi Y. Emerging Coronavirus 2019-nCoV Pneumonia. Radiology. 2020;0(0):200274. https://doi.org/10.1148/radiol.2020200274. PubMed PMID: 32027573.

13. Shi H, Han X, Jiang N, Cao Y, Alwalid O, Gu J, Fan Y, Zheng C. Radiological findings from 81 patients with COVID-19 pneumonia in Wuhan, China: a descriptive study. Lancet Infect Dis. 2020;20(4):425-34.

14. The notice of launching guideline on diagnosis and treatment of the novel coronavirus pneumonia (NCP). 6th edition.: National Health Commission of the People's Republic of China. http://www.nhc.gov.cn/yzygj/s7653p/202 003/46c9294a7dfe4cef80dc7f5912eb1989.shtml. Accessed 1 May 2020.

15. Bai Y, Yao L, Wei T, Tian F, Jin D-Y, Chen L, Wang M. Presumed Asymptomatic Carrier Transmission of COVID-19. JAMA. 2020. https://doi. org/10.1001/jama.2020.2565.

16. Meng H, Xiong R, He R, Lin W, Hao B, Zhang L, Lu Z, Shen X, Fan T, Jiang W, Yang W, Li T, Chen J, Geng Q. CT imaging and clinical course of asymptomatic cases with COVID-19 pneumonia at admission in Wuhan, China. J Infect. 2020. https://doi.org/10.1016/j.jinf.2020.04.004 Epub 2020/ 04/16. PubMed PMID: 32294504; PubMed Central PMCID: PMCP MC7152865.

17. Ai T, Yang Z, Hou H, Zhan C, Chen C, Lv W, Tao Q, Sun Z, Xia L. Correlation of chest CT and RT-PCR testing in coronavirus disease 2019 (COVID-19) in China: a report of 1014 cases. Radiology. 2020;0(0):200642. https://doi.org/ 10.1148/radiol.2020200642. PubMed PMID: 32101510.

18. Steinberger S, Lin B, Bernheim A, Chung M, Gao Y, Xie Z, Zhao T, Xia J, Mei $X$, Little BP. CT Features of Coronavirus Disease (COVID-19) in 30 Pediatric Patients. Am J Roentgenolo. 2020:1-9. https://doi.org/10.2214/AJR.20.23145.

19. Hope MD, Raptis CA, Shah A, Hammer MM, Henry TS. A role for CT in COVID-19? What data really tell us so far. Lancet. 2020;395(10231):1189-90. https://doi.org/10.1016/S0140-6736(20)30728-5.

20. ACR Recommendations for the use of Chest Radiography and Computed Tomography (CT) for Suspected COVID-19 Infection: American College of Radiology. https://www.acr.org/Advocacy-and-Economics/ACR-Position- 
Statements/Recommendations-for-Chest-Radiography-and-CT-forSuspected-COVID19-Infection. Accessed 5 June 2020.

21. The role of CT in patients suspected with COVID-19 infection: The Royal College of Radiologists. https://www.rcr.ac.uk/college/coronavirus-covid-19what-rcr-doing/clinical-information/role-ct-chest/role-ct-patients. Accessed 5 June 2020.

22. Canadian Society of Thoracic Radiology and the Canadian Association of Radiologists'Statement on COVID -19: Canadian Association of Radiologists. https://car.ca/news/canadian-society-of-thoracic-radiology-andcanadian-association-of-radiologists-statement-on-covid-19/. Accessed 5 June 2020.

23. Chen X, Tang Y, Mo Y, Li S, Lin D, Yang Z, Yang Z, Sun H, Qiu J, Liao Y, Xiao J, Chen X, Wu X, Wu R, Dai Z. A diagnostic model for coronavirus disease 2019 (COVID-19) based on radiological semantic and clinical features: a multi-center study. Eur Radiol. 2020;30:4893-4902. https://doi.org/10.1007/ s00330-020-06829-2.

24. Zhang J-F, Yan K, Ye H-H, Lin J, Zheng J-J, Cai T. SARS-CoV-2 turned positive in a discharged patient with COVID-19 arouses concern regarding the present standard for discharge. Int J Infect Dis. 2020. https://doi.org/10. 1016/j.ijid.2020.03.007.

25. An J, Liao X, Xiao T, Qian S, Yuan J, Ye H, Qi F, Shen C, Liu Y, Wang L, Cheng X, Li N, Cai Q, Wang F, Chen J, Liu Y, Wang Y, Zhang F, Fu Y, Tan X, Liu L, Zhang Z. Clinical characteristics of the recovered COVID-19 patients with re-detectable positive RNA test. medRxiv. 2020:2020.03.26.20044222. https://doi.org/10.1101/2020.03.26.20044222.

26. Fu W, Chen Q, Wang T. Letter to the Editor: Three cases of redetectable positive SARS-CoV-2 RNA in recovered COVID-19 patients with antibodies. J Med Virol. 2020;n/a(n/a). https://doi.org/10.1002/jmv.25968.

27. Cao H, Ruan L, Liu J, Liao W. The clinical characteristic of eight patients of COVID-19 with positive RT-PCR test after discharge. J Med Virol. 2020;n/a(n/ a). https://doi.org/10.1002/jmv.26017.

28. Chen D, Xu W, Lei Z, Huang Z, Liu J, Gao Z, Peng L. Recurrence of positive SARS-CoV-2 RNA in COVID-19: A case report. Int I Infect Dis 2020;93:297299. https://doi.org/10.1016/j.ijid.2020.03.003.

\section{Publisher's Note}

Springer Nature remains neutral with regard to jurisdictional claims in published maps and institutional affiliations.

Ready to submit your research? Choose BMC and benefit from:

- fast, convenient online submission

- thorough peer review by experienced researchers in your field

- rapid publication on acceptance

- support for research data, including large and complex data types

- gold Open Access which fosters wider collaboration and increased citations

- maximum visibility for your research: over $100 \mathrm{M}$ website views per year

At $\mathrm{BMC}$, research is always in progress.

Learn more biomedcentral.com/submissions 